\title{
PENGARUH GAYA KEPEMIMPINAN, MOTIVASI, DAN KEPUASAN KERJA TERHADAP KINERJA KARYAWAN (PADA BADAN PENELITIAN DAN PENGEMBANGAN KEMENTERIAN DALAM NEGERI)
}

\author{
Umi Rusilowati ${ }^{*}$, Fifth Ernawati ${ }^{* *}$ \\ Email : umi_rusilowati@yahoo.com
}

\begin{abstract}
ABSTRAK
PENGARUH GAYA KEPEMIMPINAN, MOTIVASI, DAN KEPUASAN KERJA TERHADAP KINERJA KARYAWAN (PADA BADAN PENELITIAN DAN PENGEMBANGAN KEMENTERIAN DALAM NEGERI). Penelitian ini bertujuan untuk mengetahui dan menganalisis pengaruh gaya kepemimpinan, motivasi dan kepuasan kerja secara parsial maupun simultan terhadap Kinerja di Litbang Kemendageri. Metode Penelitian ini menggunakan analisis deskriptif dan penelitian asosiatif Kuantitatif, teknik analisis data yang digunakan dalam penelitian ini yaitu : uji kualitas data (validitas, reliabilitas, dan uji asumsi klasik) dan uji hipotesis (uji parsial t, uji simultan F). Pengambilan sampel menggunakan Rumus Slovin dengan populasi seluruh pegawai Balitbang (PNS dan pegawai kontrak) yang berjumlah 257 orang. Hasil penelitian menunjukkan Gaya Kepemimpinan (X1) berpengaruh positif dan signifikan terhadap Kinerja ( $Y$ ) pegawai Balitbang Kemendagri.Motivasi (X2) berpengaruh positif dan signifikan terhadap Kinerja (Y) pegawai balitbang Kemendagri.Kepuasan kerja (X3) berpengaruh positif dan signifikan terhadap Kinerja (Y) pegawai Balitbang Kemendagri.Gaya kepemimpinan (X1), Motivasi (X2) dan Kepuasan Kerja (X3) berpengaruh positif dan signifikan secara bersama-sama terhadap Kinerja $(Y)$ pegawai Balitbang Kemendagri.

Kata Kunci: Gaya Kepemimpinan, Motivasi, Kepuasan Kerja, Kinerja.
\end{abstract}

\begin{abstract}
THE INFLUENCE OF LEADERSHIP STYLE, MOTIVATION, AND WORK SATISFACTION ON EMPLOYEE PERFORMANCE (IN THE RESEARCH AND DEVELOPMENT MINISTRY OF INTERNAL AFFAIRS). This study aims to determine and analyze the effect of partial and simultaneous leadership style, motivation and job satisfaction on the Ministry of Trade's Performance in Research and Development. This research method uses descriptive analysis and quantitative associative research, data analysis techniques used in this research are: data quality test (validity, reliability, and classical assumption test) and hypothesis testing (partial $t$ test, simultaneous $F$ test). Sampling using the Slovin Formula with a population of all Balitbang employees (PNS and contract employees) totaling 257 people. The results showed Leadership Style (X1) had a positive and significant effect on the Performance ( $Y$ ) of the employees of the Ministry of Internal Affairs of the Ministry of Home Affairs. Motivation (X2) had a positive and significant effect on the Performance $(Y)$ of the Ministry of Home Affairs Balitbang employees. Job satisfaction (X3) had a positive and significant effect on Performance $(Y)$ Balitbang Ministry of Home Affairs employees. Leadership styles (X1), Motivation (X2) and Job Satisfaction (X3) have a positive and significant effect on the Performance ( $Y$ ) of employees of the Research and Development Ministry of Internal Affairs.
\end{abstract}

Keywords: Leadership Style, Motivation, Job Satisfaction, Performanceof Employee.

*) Dosen Program Studi Magister Manajemen - UNPAM

${ }^{* *}$ ) Alumni Program Studi Magister Manajemen - UNPAM 


\section{PENDAHULUAN.}

\section{A. Latar Belakang.}

Gaya kepemimpinan adalah pola menyeluruh dari tindakan seorang pemimpin. Konsep Gaya Kepemimpinan di Badan Litbang Kemendagri cendrung lebih mengerucut pada gaya kepemimpinan demokratis sifat kepemimpinannya lebih terbuka. Hal ini ditandai oleh perumusan kebijakan ataupun kegiatan yang dilakukan secara bersama (musyawarah) kepada divisi, oleh karena itu seorang pemimpin lebih banyak memberi semangat dan mendorong anggota agar berprestasi melalui reward (penghargaan) berdasarkan sikap objektifitas dan berdasarkan fakta yang ada, sehingga dengan kondisi tersebut setiap anggota lebih banyak berpeluang untuk mengemukakan ide, pikiran serta kreatifitasnya didalam mendukung kebijakan dan untuk mencapai hasil yang maksimal dalam rangka mewujudkan tujuan yang telah ditetapkan. Selain itu, karena situasi kepemimpinan demokratis lebih terbuka maka setiap pegawai menjadi lebih leluasa pula untuk bekerjasama dengan siapapun tanpa adanya batasan-batasan dari pemimpin.

Fakta kepemimpinan di Balitbang Kemendagri masih bersifat Top Down dan kental dengan nuansa Struktural tidak berbasis fungsional yang mengedepankan Bottom Up yaitu mengedepankan kepemimpinan Fungsional.

Motivasi adalah dorongan yang positif yang sangat menentukan kinerja seseorang. Motivasi sering diartikan semangat, pengertian motivasi secara sederhana berupa alasan untuk melakukan sesuatu. Motivasi dengan fasilitas pendukung adalah salah satu dari indikator, dengan adanya fasilitas pendukung pegawai agar dapat bekerja dengan tenang sehingga menghasilkan keluaran atau output kerja yang maksimal. Adapun fasilitas yang terdapat di Balitbang diantaranya adanya BPJS, kendaraan operasional, security 24 jam, cctv, reimburse pengobatan, koperasi, pensiun (hanya pegawai tetap)

Kepuasan Kerja ialah cara pegawai merasakan dirinya atau pekerjaannya. Jadi kepuasan kerja ialah perasaan yang menyokong maupun tidak menyokong dalam diri pegawai yang berhubungan dengan pekerjaan maupun kondisi dirinya

Kinerja Pegawai juga dapat diartikan sebagai sebuah pandangan untuk selalu perpikir, kerja keras, bekerja sepenuh waktu, disiplin, jujur, loyalitas tinggi, dan penuh dedikasi demi untuk keberhasilan pekerjaannya.

Faktadi Balitbang nilai-nilai yang dapat mempengaruhi memotivasi karyawan tidak selalu berjalan dengan baik, hal ini masih terjadi ketidakadilan dalam pemberian reward dan punishment terhadap pegawainya. Hal ini kiranya yang perlu perhatian bagi banyak instansi atau perusahaan dalam pemberian nilai-nilai yang dapat mempengaruhi memotivasi kepada pegawai.

Fakta kepuasan kerja yang ada pada pegawai di lingkungan Balitbang Kemendagri antara lain ditunjukan melalui perilaku yang mengarah pada adanya pegawai yang meninggalkan organisasi, termasuk mencari posisi baru atau pindah kerja dengan permintaan sendiri. Dengan kata lain banyak pegawai yang 
mengajukan pindah kerja ke luar Balitbang Kemendagri atau pindah antar pusat karena permintaan sendiri dikarenakan ketidak cocokan dengan pimpinannya.

Terjadinyaperpindahan (turnover) pegawai pada Balitbang Kemendagri karena tidak puas dalam bekerja, pada tahun 2016 mengalami peningkatan. Akibat terjadinya turnoverdari Balitbang ke komponen Kemendagri dan sebaliknya dari komponen Kemendagri ke Balitbang, ini pihak Balitbang Kemendagri harus memperhatikan kepuasan kerja pegawainya untuk menekan angka pegawai yang mengundurkan diri dan mencoba mencari pekerjaan lain.

\section{B. RUMUSAN MASALAH}

Berdasarkan latar belakang masalah yang telah diungkapkan sebelumnya, maka peneliti dapat merumuskan masalah pada penelitian ini adalah sebagai berikut

1. Apakah gaya kepemimpinan berpengaruh positif dan signifikan terhadap Kinerja pegawai Badan Litbang Kemendageri ?

2. Apakah motivasi berpengaruh positif dan signifikan terhadap kinerja pegawai Badan Litbang Kemendageri?

3. Apakah kepuasan kerja berpengaruh positif dan signifikan terhadap Kinerja karyawan di Litbang Kemendageri?

4. Apakahgaya kepemimpinan, motivasi dan kepuasan kerja secara simultan berpengaruh positif dan signifikan terhadap kinerja pegawai Badan Litbang Kemendageri?

\section{Kerangka Berpikir}

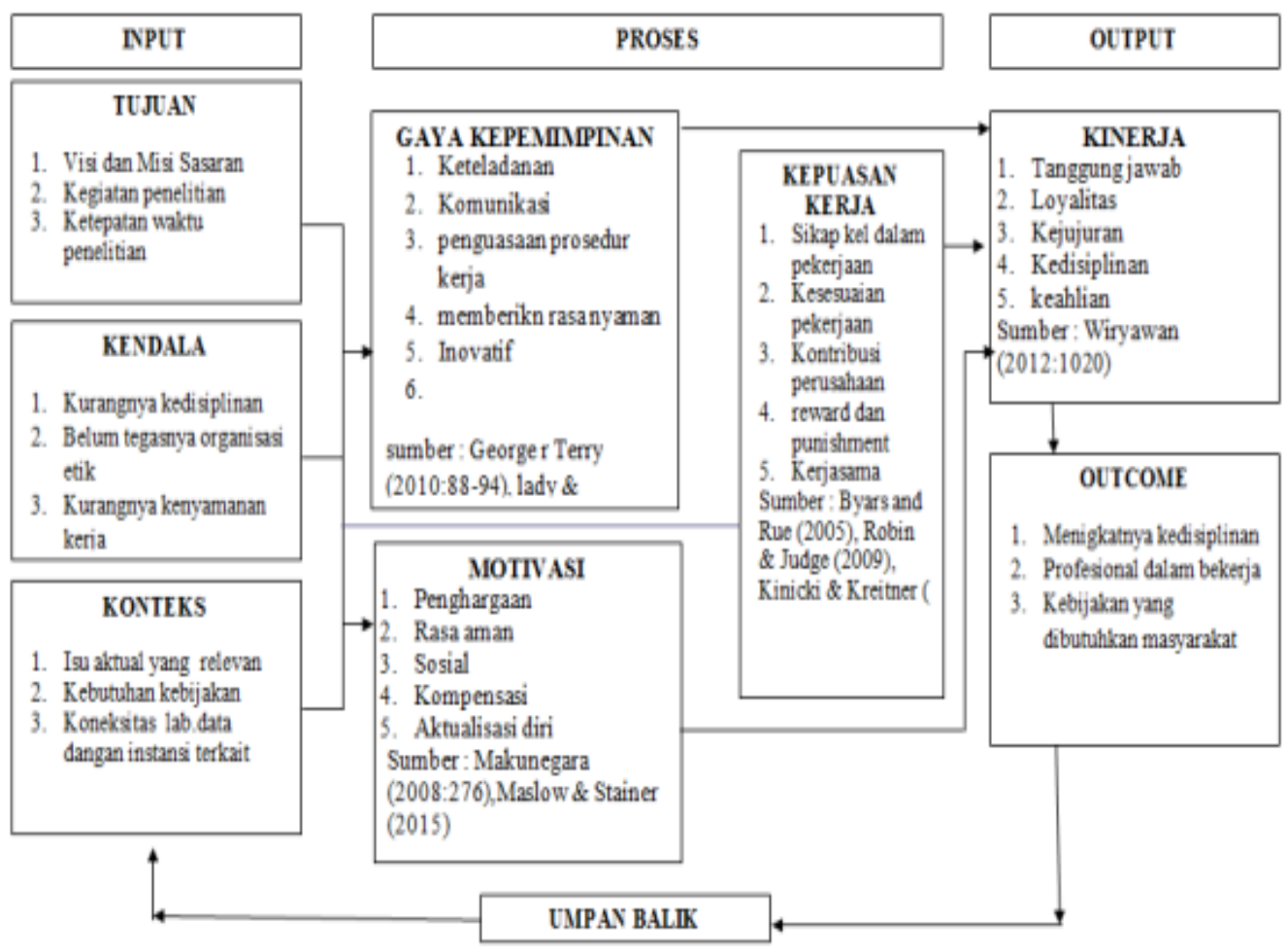

Gambar 1. : Kerangka Pemikiran 


\section{METODE}

Pendekatan yang digunakan dalam penelitian adalah studi kasus sedangkan sifat penelitian asosiatif (hubungan) yaitu penelitian yang bertujuan untuk mengetahui hubungan antara dua variabel atau lebih. Penelitian ini adalah penelitian populasi.

Pergerakan ini diawali dengan studi pendahuluan yang ditujukan untuk mengidentifikasi masalah dan menyusun kerangka penelitian serta menetapkan hipotesis

Populasididalampenelitianiniadalah karyawan Balitbang Kemendagri semua Pusat Litbang berjumlah 257 karyawan

Karena jumlah populasi lebih dari 100 orang, maka penarikan sampel dalam penelitian ini menggunakan sampel secara acak (random sampling). Sedangkan teknik pengambilan sampel menggunakan rumus Slovin.

Dari jumlah populasi sebanyak 257 karyawan, setelah menentukan menggunakan rumus slovin dengan tingkat eror 0,05 maka sampel pada penelitian iniberjumlah 156 orang dan teknis pada penyebaran quesioner dilakukan secara random

\section{ANALISIS DAN PEMBAHASAN}

\section{A. Pengaruh Gaya Kepemimpinan terhadap Kinerja}

Hasil pengolahan uji t untuk mengetahui pengaruh Gaya Kepemimpinan terhadap Kinerja adalah sebagai berikut:

Tabel 1. : Hasil Uji-t antara Gaya Kepemimpinandengan Kinerja Coefficients $^{\mathrm{a}}$

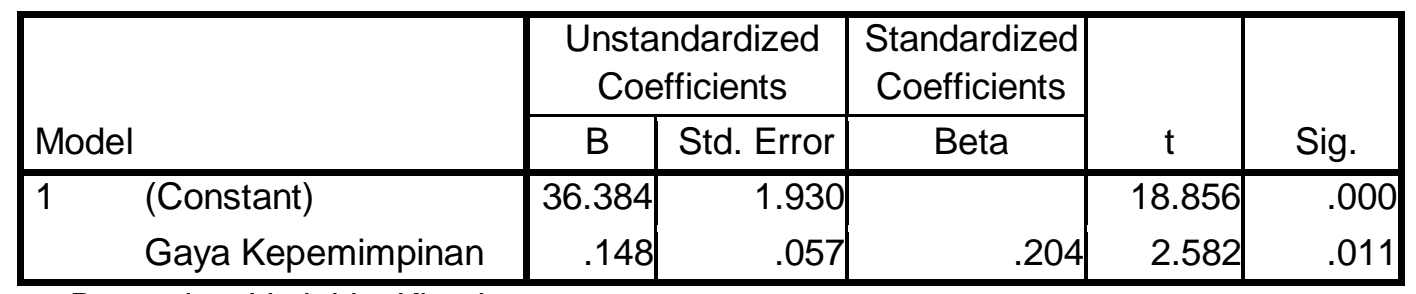

a. Dependent Variable: Kinerja

Nilai t hitung $=2.582$, tingkat signifikansi $\alpha=0,05$

$\mathrm{df}=\mathrm{n}-\mathrm{k}=156-3=153$

Uji dilakukan dua sisi (two tail), sehingga nilai t tabel adalah 1.6548

Berdasarkan uraian diatas maka keputusannya karena t hitung 2.582 lebih besar dari t tabel 1.6548 maka Hipotesis Pertama diterima. Terlihat pada kolom signifikansi pada tabel di atas adalah sebesar 0.011 dan lebih kecil dari nilai probabilitas 0.05 maka dapat disimpulkan bahwa Gaya Kepemimpinan berpengaruh signifikan terhadap Kinerja, yang artinya bahwa tinggi rendahnya Gaya Kepemimpinan mempengaruhi Kinerja.

\section{B. Pengaruh Motivasi terhadap Kinerja}

Hasil pengolahan uji t untuk mengetahui pengaruh Motivasi terhadap Kinerja adalah sebagai berikut: 
Tabel 2. : Hasil Uji-t antara Motivasi dengan Kinerja Coefficients $^{\mathrm{a}}$

\begin{tabular}{|c|c|c|c|c|c|c|}
\hline \multirow{2}{*}{\multicolumn{2}{|c|}{ Model }} & \multicolumn{2}{|c|}{$\begin{array}{c}\text { Unstandardized } \\
\text { Coefficients }\end{array}$} & \multirow{2}{*}{$\begin{array}{c}\begin{array}{c}\text { Standardized } \\
\text { Coefficients }\end{array} \\
\text { Beta }\end{array}$} & \multirow[b]{2}{*}{$\mathrm{T}$} & \multirow[b]{2}{*}{ Sig. } \\
\hline & & $B$ & Std. Error & & & \\
\hline 1 & (Constant) & 17.438 & 2.660 & & 6.555 & .000 \\
\hline & Motivasi & .583 & .065 & .588 & 9.013 & .000 \\
\hline
\end{tabular}

Dependent Variable: Kinerja

Nilai t hitung $=9.013$, tingkat signifikansi $\alpha=0,05$

$\mathrm{df}=\mathrm{n}-\mathrm{k}=156-3=153$

Uji dilakukan dua sisi (two tail), sehingga nilai t tabel adalah 1.6548

Berdasarkan uraian diatas maka keputusannya karena t hitung 9.013 lebih besar dari t tabel 1.6548 maka HipotesisKeduaditerima. Terlihat pada kolom signifikansi pada tabeldi atas adalah sebesar 0.000 dan lebih kecil dari nilai probabilitas 0.05 maka dapat disimpulkan bahwa Motivasiberpengaruh signifikan terhadap Kinerja. Yang artinya bahwa tinggi rendahnya Motivasimempengaruhi Kinerja.

\section{Pengaruh Kepuasan Kerja terhadap Kinerja}

Hasil pengolahan uji t untuk mengetahui pengaruh Kepuasan Kerja (X3) terhadap

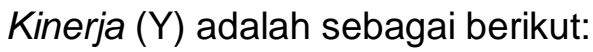

Tabel 3. : Hasil Uji-t antaraKepuasanKerjadengan Kinerja Coefficients $^{\mathrm{a}}$

\begin{tabular}{|c|c|c|c|c|c|c|}
\hline \multirow{2}{*}{\multicolumn{2}{|c|}{ Model }} & \multicolumn{2}{|c|}{$\begin{array}{l}\text { Unstandardized } \\
\text { Coefficients }\end{array}$} & $\begin{array}{c}\text { Standardized } \\
\text { Coefficients }\end{array}$ & \multirow[b]{2}{*}{ T } & \multirow[b]{2}{*}{ Sig. } \\
\hline & & $B$ & Std. Error & Beta & & \\
\hline \multirow[t]{2}{*}{1} & (Constant) & 17.745 & 2.261 & & 7.850 & .000 \\
\hline & Kepuasan Kerja & .580 & .055 & .645 & 10.482 & .000 \\
\hline
\end{tabular}

a. Dependent Variable: Kinerja

Nilai t hitung $=10.482$, tingkat signifikansi $\alpha=0,05$

$\mathrm{df}=\mathrm{n}-\mathrm{k}=156-3=153$

Uji dilakukan dua sisi (two tail), sehingga nilai t tabel adalah 1.6548

Berdasarkan uraian diatas maka keputusannya karena t hitung 10.482 lebih besar dari t tabel 1.6548 maka HipotesisKetigaditerima. Terlihat pada kolom signifikansi pada tabeldi atas adalah sebesar 0.000 dan lebih kecil dari nilai probabilitas 0.05 maka dapat disimpulkan bahwa KepuasanKerjaberpengaruh signifikan terhadap Kinerja, yang artinya bahwa tinggi rendahnya Kepuasan Kerja mempengaruhi Kinerja.

\section{Pengaruh Secara Simultan Gaya Kepemimpinan, Motivasidan Kepuasan Kerja terhadap Kinerja}

Hasil pengolahan uji hipotesis secara simultan untuk mengetahui pengaruh antara Gaya Kepemimpinan, Motivasi dan Kepuasan Kerja terhadap Kinerja adalah : 
Tabel 4. : Hasil uji-F antara Gaya Kepemimpinan, Motivasi dan Kepuasan Kerja terhadap Kinerja.

\begin{tabular}{|c|c|c|c|c|c|c|}
\hline \multicolumn{7}{|c|}{ ANOVA $^{a}$} \\
\hline Model & & Sum of Squares & Df & Mean Square & $\mathrm{F}$ & Sig. \\
\hline 1 & Regression & 1120.596 & 3 & 373.532 & 42.682 & $.000^{\mathrm{k}}$ \\
\hline & Residual & 1330.244 & 152 & 8.752 & & \\
\hline & Total & 2450.840 & 155 & & & \\
\hline
\end{tabular}

a. Dependent Variable: Kinerja

b. Predictors: (Constant), KepuasanKerja, Gaya Kepemimpinan, Motivasi

Nilai $F$ hitung $=42.682$, tingkat signifikansi $\alpha=0,05$

df $1=$ Variabel $-1=3-1=2$

df $2=n-$ variabel $-1=156-2-1=153$

Dari data di atas maka diperoleh nila $\mathrm{F}$ tabel adalah sebesar 3.06.

Berdasarkan uraian diatas maka keputusannya karena $F$ hitung 42.682 lebih besar dari $\mathrm{F}$ tabel 3.06.Terlihat pada kolom signifikansi pada tabel di atas adalah sebesar $0.000^{\mathrm{b}}$ dan lebih kecil dari nilai probabilitas 0.05 maka dapat disimpulkan bahwa antara Gaya Kepemimpinan, Motivasi dan Kepuasan Kerja berpengaruh signifikan terhadap Kinerja.

\section{KESIMPULAN DAN SARAN}

\section{A. Kesimpulan :}

Berdasarkan hasil penelitiandiBalitbang Kemendagri dengan 4 pengujian Hipotesis yang terdiridari 3 pengujian secara parsial dan 1 pengujian secara simultan, maka dapat diambil kesimpulan sebagai berikut:

1. Gaya Kepemimpinan berpengaruh signifikan terhadap Kinerja. Hal ini dibuktikan dengan hasil Pengujian hipotesis dimana diperoleh Nilai t hitung 2.582 lebih besar dari t tabel 1.6548, lalu nilai signifikansinya sebesar 0.011 dan lebih kecil dari nilai probabilitas 0.05 , dan hubungannya bersifat positif.

2. Motivasi berpengaruh signifikan terhadap Kinerja. Hal ini dibuktikan dengan hasil pengujian hipotesis dimana t hitung 9.013 lebih besar dari t tabel 1.6548, lalu nilai signifikansi sebesar 0.000 dan lebih kecil dari nilai probabilitas 0.05 , dan hubungannya bersifat positif.

3. Kepuasan Kerja berpengaruh signifikan terhadap Kinerja. Hal ini dibuktikan dimana t hitung 10.482 lebih besar dari t tabel 1.6548, lalu nilai signifikansinya sebesar 0.000 dan lebih kecil dari nilai probabilitas 0.05 , dan hubungannya bersifat positif.

4. Secara simultan Gaya Kepempinan, Motivasi dan Kepuasan Kerja Berpengaruh Signifikan secara simultan terhadap Kinerja, hal ini dibuktikan dengan hasil pengujian hipotesis dimana $F$ hitung 42.682 lebih besar dariF tabel 3.06, lalu nilai signifikansinya adalah sebesar $0.000 \mathrm{~b}$ dan lebih kecil dari nilai probabilitas 0.05 , dan hubungannya bersifat positif. 


\section{B. Saran}

1. Kepemimpinan di Balitbang Kemendagri hendaknya selalu memberikan keteladanan dan bisa berfikir inovatif, serta mempunyai kepedulian sosial terhadap semua yang terkait dengan kemajuan organisasi. Inovasi yang dilakukan harus berbasis pengetahuan.

2. Motivasi dan Kepuasan kerja terhadap pegawai di Balitbang Kemendagri hendaknya lebih diperhatikan dan dapat mendorong profesionalisme dan aktualisasi diri karyawan, akuntabilitas karyawan di Balitbang Kemendagri sangat dibutuhkan dalam mempertanggung jawabkan pekerjaan penelitian

3. Kinerja pegawai Balitbang Kemendagri hendaknya lebih ditingkatkan akan rasa tanggung jawabnya masing-masing dalam menjalankan tugasnya dan sikap positif karyawan terus dibangun termasuk loyalitas dalam bekerja.

\section{DAFTAR PUSTAKA}

Alwi, 2001, Manajemen Sumber Daya Manusia Keunggulan, BPFEUGM, Yogyakara.

Anwar Prabu Mangkunegara, 2006, Evaluasi Kinerja SDM, Refika Aditama,Bandung.

Ardana, Mujiati dan Utama, 2012, Manajemen Sumber Daya Manusia, Grahallmu, Yogyakarta.

Arikunto, Suharsimi, 2006, Prosedur Penelitian suatu pendekatan Praktik, Jakarta : PT Rineka Cipta.

Abraham H. Maslow, 2010, Motivation and Personality. Rajawali, Jakarta.

Foster Bill, 2001, Pembinaan Untuk Meningkatkan Kinerja Karyawan, PPM,Jakarta.

George R. Terry, 2010, Prinsip prinsip Manajemen, Bumi aksara, Jakarta.

Ghozali, 2005, Analisis Multivariant dengan Program SPSS, UNDIP, Semarang.

Husein Umar. 2008, Metode Riset Bisnis, Gramedia Pustaka Utama, Jakarta.

Robbins dan Coulter, 2007, Manajemen Jilid Satu, Rineka Cipta, Jakarta

Silalahi, Ulber. 2009. Metode Penelitian Sosial. Bandung; PT. Refika Aditama

Sugiyono,2008, Metode Penelitian Kuantitatif Kualitatif dan $R \& D$, Alfabeta,Bandung.

Sutrisno, Edy, 2010, Budaya Organisasi, Jakarta : Kencana Prenada Media Group.

Tella, Adeyinka, 2007, Work Motivation, Job Satisfaction, and Organisational Commitment of Library Personnel in Academic and Research Libraries in Oyo State, Nigeria, Library Philosophy and Practice 2007 (April).

Veithzal Rivai. 2004. Manajemen Sumber Daya Manusia Untuk Perusahaan Dari Teori Ke Praktik. PT. Raja Grafindo Persada, Jakarta 